\title{
STATUS KEBERSIHAN MULUT PADA PENGGUNA ALAT ORTODONTI CEKAT BERDASARKAN ORAL HYGIENE INDEX SIMPLIFIED DI SEKOLAH MENENGAH ATAS NEGERI 1 MANADO
}

\author{
${ }^{1}$ Charlito J. R. Galag \\ ${ }^{2}$ P. S. Anadita \\ ${ }^{2}$ Olivia Waworuntu
}

\author{
${ }^{1}$ Kandidat Skripsi Program Studi Pendidikan Dokter Gigi Fakultas Kedokteran \\ ${ }^{2}$ Program Studi Pendidikan Dokter Gigi Universitas Sam Ratulangi Manado \\ Email: charlitogalag@gmail.com
}

\begin{abstract}
Oral hygiene is an important factor that must be maintained by users of fixed orthodontic appliance. Things that affect oral hygiene fixed orthodontic appliance users are the components of the fixed orthodontic appliance that is difficult to clean. The risks from poor oral hygiene can increase the occurrence of dental caries and the other periodontal diseases. This study is a descriptive research with the aim of research to find out the status of oral hygiene fixed orthodontic appliance users based Oral Hygiene Index Simplified (OHI-S). Research conducted at SMAN 1 Manado with a sample of 36 people and the sampling is done by total sampling method. The results of this study of 36 respondents showed an average score of OHI-S 1.3 with a total score Debris Index Simplified (DI-S) score of 0.9 and Calculus Index Simplified (CI-S) 0.4 classified in moderate oral hygiene status. Oral hygiene status on average on students fixed orthodontic appliance users in SMAN 1 Manado based Oral Hygiene Index Simplified (OHI-S) classified in the moderate category with a score of 1.3.

Keywords: oral hygiene, fixed orthodontic appliance, OHI-S
\end{abstract}

\begin{abstract}
Abstrak: Kebersihan mulut merupakan faktor penting yang harus dijaga oleh pengguna alat ortodonti cekat. Hal yang mempengaruhi kebersihan mulut pengguna alat ortodonti cekat ialah komponen-komponen pada alat ortodonti cekat yang sulit dibersikan. Resiko yang timbul akibat kebersihan mulut yang buruk dapat meningkatkan terjadinya karies gigi dan penyakit periodontal lainnya. Penelitian ini merupakan penelitian deskriptif dengan tujuan penelitian untuk mengetahui status kebersihan mulut pengguna alat ortodonti cekat berdasarkan Oral Hygiene Index Simplified (OHI-S). Penelitian dilakukan di SMA Negeri 1 Manado dengan jumlah sampel 36 orang dan pengambilan sampel dilakukan dengan metode total sampling. Hasil penelitian menunjukkan dari 36 responden rata-rata skor OHI-S 1,3 dengan jumlah skor Debris Index Simplified (DI-S) 0,9 dan skor Calculus Index Simplified (CI-S) 0,4 tergolong pada status kebersihan mulut sedang. Status kebersihan mulut rata-rata pada siswa-siswi pengguna alat ortodonti cekat di sekolah menengah atas Negeri 1 Manado berdasarkan Oral Hygiene Index Simplified (OHI-S) tergolong pada kategori sedang dengan skor 1,3 .
\end{abstract}

Kata kunci: kebersihan mulut, alat ortodonti cekat, OHI-S

Perawatan ortodonti bertujuan memperbaiki susunan gigi dan rahang serta estetik wajah. Penampilan wajah yang kurang baik dapat disebabkan oleh susunan gigi yang tidak rapi sehingga menimbulkan masalah psikologis, seperti kurangnya rasa percaya diri.

Seiring berkembangnya zaman, 
masyarakat luas banyak menggunakan alat ortodonti cekat maupun lepasan. Kalangan luas belum banyak mengetahui efek samping dari penggunaan alat ortodonti yang membuat seseorang harus berhati-hati saat perawatan alat ortodonti. ${ }^{1}$

Pengguna alat ortodonti sangat rentan mengalami kebersihan mulut yang buruk. Hal ini dipengaruhi oleh komponenkomponen pada alat ortodonti yang sulit dibersihkan. Resiko yang timbul akibat kebersihan mulut yang buruk dapat meningkatkan terjadinya karies dan penyakit periodontal lainnya. $^{2}$

Terdapat beberapa cara mengukur status kebersihan rongga mulut salah satunya dengan skor OHI-S (Oral Hygiene Index Simplified). Peneliti menggunakan indeks ini karena indeks ini lebih mudah dan sederhana dibandingkan indeks-indeks yang lain. Pengukuran OHI-S menggunakan metode yang ditemukan oleh Greene dan dan Vermilion. OHI-S ialah indeks untuk mengukur daerah gigi yang tertutup oleh debris dan kalkulus. Cara pengukuran OHI-S ialah dengan menambahkan Debris Indeks (DI) dengan Calculus Indeks (CI). ${ }^{3}$ Skor OHI-S pada penggunaan alat ortodonti harus berada pada kategori yang baik pada penggunaan alat ortodonti. Skor OHI-S yang baik bisa didapatkan dengan cara perawatan gigi yang baik dan benar, seperti dengan cara menyikat dengan benar dan teratur 2-3 kali dalam sehari serta waktu menyikat gigi yang tepat yaitu sesudah makan dan sebelum tidur.

\section{METODE PENELITIAN}

Penelitian ini bersifat deskriptif dengan rancangan potong lintang. Penelitian dilaksanakan di SMAN 1 pada bulan Desember 2014 - Maret 2015. Populasi penelitian ini yaitu semua siswa-siswi SMAN 1 Manado yang menggunakan alat ortodonti cekat berjumlah. Sampel penelitian ini seluruh populasi yang memenuhi kriteria inklusi berjumlah 36 orang. Pengambilan sampel dilakukan dengan metode total sampling.

Pemeriksaan kebersihan mulut dilakukan dengan Oral Hygiene Index
Simplified (OHI-S) ialah status kebersihan mulut yang merupakan jumlah dari Debris Indeks(DI) dan Calculus Indeks(CI). Kriteria skor 0,0 - 1,2 termasuk baik, 1,3 3,0 dikatakan sedang dan 3,1 - 6,0 di kriteria buruk.

\section{HASIL PENELITIAN DAN BAHASAN}

Subjek penelitian berjumlah 36 siswa. Berdasarkan karakteristik jenis kelamin jumlah subjek perempuan lebih banyak dibandingkan dengan laki-laki (Tabel 1).

Tabel 1. Karakteristik subjek berdasarkan jenis kelamin

\begin{tabular}{ccc}
\hline Jenis Kelamin & Jumlah & $(\%)$ \\
\hline Laki-Laki & 5 & 13,9 \\
Perempuan & 31 & 86,1 \\
Total & 36 & 100 \\
\hline
\end{tabular}

Data pada Tabel 2 menunjukan bahwa paling banyak siswa dengan usia 17 tahun (38,89\%) dan paling sedikit usia 14 dan 18 tahun (masing-masing 2,78\%).

Tabel 2. Karakteristik subjek berdasarkan usia

\begin{tabular}{ccc}
\hline Usia & Jumlah & $(\%)$ \\
\hline 14 tahun & 1 & 2,78 \\
15 tahun & 7 & 19,44 \\
16 tahun & 13 & 36,11 \\
17 tahun & 14 & 38,89 \\
18 tahun & 1 & 2,78 \\
Total & 36 & 100 \\
\hline
\end{tabular}

Distribusi status kebersihan gigi dan mulut dapat dibedakan berdasarkan kriteria baik, sedang dan buruk berdasarkan OHI-S. Hasil penelitian menunjukan sebagian besar responden $23(69,44 \%)$ memiliki OHI-S sedang dengan skor 1,8 , dan tidak terdapat responden dengan kategori buruk (Tabel 3). Hasil penelitian untuk mengetahui rata-rata status kebersihan gigi dan mulut seluruh subjek penelitian berdasarkan skor OHI-S dengan menjumlahkan skor DI-S dan CI-S. Dari 36 responden menunjukan rata-rata skor OHI-S 1,3 dengan jumlah skor DI-S 0,9 dan skor CI-S 0,4 tergolong pada status kebersihan gigi dan mulut sedang. 
Tabel 3. Distribusi status kebersihan gigi dan mulut pengguna alat ortodonti cekat

\begin{tabular}{ccccc}
\hline OHI-S & Jumlah & $\begin{array}{c}\text { (\%) } \\
\end{array}$ & $\begin{array}{c}\text { Skor } \\
\text { OHI- } \\
\text { S }\end{array}$ & $\begin{array}{c}\text { Status } \\
\text { kebersihan } \\
\text { gigi dan } \\
\text { mulut }\end{array}$ \\
\hline Baik & 11 & 30,5 & 0,9 & Baik \\
Sedang & 23 & 69,44 & 1,8 & Sedang \\
Buruk & 0 & 0 & 0 & - \\
Rerata & 36 & 100 & $\begin{array}{c}2,7 / 2 \\
\text { s. }\end{array}$ & Sedang \\
& & & $=1,3$ & \\
\hline
\end{tabular}

\section{BAHASAN}

Berdasarkan hasil penelitian (Tabel 3) pada seluruh subjek penelitian yang terdiri dari 36 responden, terdapat 11 (30,56\%) responden dengan tingkat kebersihan gigi dan mulut baik, 25 (69,44\%) responden dengan kriteria sedang dan tidak terdapat kriteria buruk. Secara keseluruhan rata-rata kebersihan mulut tergolong pada kriteria sedang dengan hasil perhitungan OHI-S 1,3. Penelitian yang sama juga parnah dilakukan oleh Momongan pada tahun 2014 dengan 39 responden dan tidak terdapat responden dengan kriteria buruk. ${ }^{4}$ Data di atas menunjukkan bahwa status kebersihan mulut responden sudah memperhatikan akan kebersihan mulutnya, karena tidak terdapat responden dengan kriteria buruk. Masih belum optimal, karena hasil perhitungan OHI-S 1,3 pada kriteria sedang.

Nilai rata-rata kebersihan gigi dan mulut pengguna alat ortodonti cekat secara keseluruhan ada pada kriteria sedang dengan hasil perhitungan OHI-S 1,3. Kebersihan mulut dipengaruhi oleh perilaku pemeliharaan kebersihan gigi dan mulut pada masing-masing individu. Menurut Widi, salah satu faktor yang memengaruhi tingkat kebersihan gigi dan mulut adalah perilaku. ${ }^{(5)}$ Perilaku dapat dibentuk dari lingkungan dan juga faktor genetik. Pembentukan perilaku yang berasal dari lingkungan dapat berupa pengalaman yang diperoleh dari lingkungan kehidupan sehari-hari, sedangkan untuk faktor genetik berupa perilaku yang diturunkan dari orang tua. ${ }^{6}$

Terdapat beberapa perilaku yang memengaruhi subjek penelitian seperti waktu dan cara menyikat gigi yang benar, menggosok gigi adalah cara yang umum dianjurkan untuk membersihkan berbagai kotoran yang melekat pada permukaan gigi dan gusi. Menyikat gigi yang benar ialah minimal dua kali sehari setiap pagi setelah makan dan malam sebelum tidur, hal ini bertujuan untuk membersihkan sisa makanan yang tertinggal pada gigi. Perilaku menggosok gigi dapat mengurangi terjadinya penyakit gigi seperti karies dan jaringan periodontal.

Jenis sikat yang digunakan, sikat gigi ortodonti memiliki desain khusus untuk membersihkan sisa-sisa makanan yang menempel pada gigi dan alat ortodonti, dikarenakan dengan menggunakan alat ini permukaan gigi cenderung kurang bersih oleh karena adanya bracket yang menempel pada permukaan gigi. Pengguna alat ortodonti cekat yang kurang disiplin dalam menjaga kebersihan mulutnya akan tergambar dari kondisi permukaan giginya yang kurang baik. ${ }^{8}$ Penelitian yang dilakukan oleh Winatha tahun 2014 menunjukan bahwa sikat gigi khusus ortodonti penurunan indeks plaknya lebih besar dibandingkan dengan sikat gigi konvensional. $^{9}$

Faktor lain yang mempengaruhi status kebersihan mulut pada pemakaian alat cekat ialah peran operator, jika perawatan dilakukan oleh dokter gigi atau dokter gigi spesialis dapat memotivasi dan intruksi selama perawatan ortodonti cekat sehingga pasien bisa lebih peduli pada kesehatan gigi dan mulut. Hal ini juga pernah dipaparkan oleh Wulandari dalam penelitiannya pada tahun 2012 di Rumah Sakit Gigi dan Mulut Universitas Indonesia. Dorongan motivasi yang diberikan dokter gigi pada pengguna alat ortodonti cekat menyebabkan terjadinya penurunan jumlah plak pada pasien yang menjalani perawatan ortodonti cekat. ${ }^{10}$ Namun dalam penelitian ini faktor motivasi kepada pasien itu sendiri tidak diteliti.

\section{SIMPULAN}

Status kebersihan mulut rata-rata pada 
siswa-siswi pengguna alat ortodonti cekat di Sekolah Menengah Atas Negeri 1 Manado berdasarkan Oral Hygiene Index Simplified (OHI-S) tergolong pada katerogi sedang dengan skor 1,3.

\section{SARAN}

1. Dapat dilakukan penelitian status kebersihan pada pengguna alat ortodonti cekat pada siswa-siswi Sekolah Menengah Atas di kecamatankecamatan lain di Kota Manado, Untuk mengoptimalkan upaya promotif dan preventif tentang kesahatan gigi dan mulut.

2. Bagi siswa-siswi pengguna alat ortodonti cekat diharapkan dapat lebih menjaga kesehatan gigi dan mulutnya agar kedapannya dapat menajadi contoh prilaku keesehatan gigi dan mulut dalam keluarga maupun lingkungan sekitarnya.

3. Bagi pihak sekolah tempat penelitian yang dilakukan agar dapat mendorong para siswa-siswi untuk dapat memepertahankan perilaku yang baik dalam menjaga dan memelihara kebersihan gigi dan mulutnya terlebih khusus pada saat melakukan perawatan ortodonti.

\section{DAFTAR PUSTAKA}
1. Ramdhani GS. Fenomena fixed orthodontic antara pemborosan dan kebutuhan. Kompasiana. [cited 27 Oktober 2014] available from : URL : http://www.kompasiana.com/fenomena lFixedOrthodonticBehelantaraPemboro sandankebutuhan_files/

\section{Al-Anezi SA, Harradine NWT.}

Quantifying plaque during orthodontic treatment. Angle Orthodontist. 2012;82:784-53.

3. Darby ML, Walsh M. Dental hygiene theory and practice. $3^{\text {rd }}$ ed. St. Louis,Missouri: Sanders Elsevier; 2010. p. 8.

4. Momongan RE. Status kebersihan gigi dan mulut siswa SMA Negeri 9 Manado pengguna alat ortodonti cekat FK Unsrat [skripsi]. Manado 2014.

5. Widi ER. Hubungan prilaku memebersikan gigi terhadap tingkat kebersihan mulut siswa sejolah dasar negeri wilaya kerja puskesmas gladak pakem kabupaten jember. JKGI. 2003:10(3). p. 10.

6. Herijulianti E, Tati SI, Sri A. Pendidikan kesehatan gigi. Jakarta: Penerbit Buku Kedokteran EGC; 2001. p. 35.

7. Purnomo I, Lestari S. Studi tentang faktorfaktor yang berhubungan dengan status kesehatan gigi dan mulut siswa smk yependa wiradesa kabupaten Pekalongan. 2013. Available from: URL

http://journal.unikal.ac.id/index.php/lpp m/article/download/263/199

8. Wowor VE. Hubungan antara status kebersihan mulut dengan status karies siswa sekolah menengah atas negeri 1 Manado. [Skripsi] Manado. 2013. h. 4

9. Winatha IM. Penggunaan sikat gigi khusus ortodontik lebih menurunkan akumulasi plak gigi daripada sikat gigi konvensional pada pengguna alat ortodontik cekat. [Skripsi] Denpasar. 2014. p. 55.

10. Wulandari NNS. Pengaruh berbagai metode motivasi pada skor oral hygiene pasien ortodonti cekat di RSGM-P FKG UI [Tesis] Jakarta; 2012. p. 42. 